This is a postprint version of the following published document:

Crespo, M., González, M., Elías, A. L., Pulickal Rajukumar, L., Baselga, J., Terrones, M. y Pozuelo, J. (2014): Ultra-light carbon nanotube sponge as an efficient electromagnetic shielding material in the GHz range. Physica Status Solidi (RRL) - Rapid Research Letters, 8 (8), pp. 698-704..

DOI: $10.1002 /$ pssr.201409151

(C) WILEY-VCH, 2014 


\title{
Ultra-light carbon nanotube sponge as an efficient electromagnetic shielding material in the $\mathrm{GHz}$ range
}

\author{
María Crespo', María González', Ana Laura Elías², Lakshmy Pulickal \\ Rajukumar', Juan Baselga', Mauricio Terrones², and Javier Pozuelo*,1
}

\footnotetext{
${ }^{1}$ Departamento de Ciencia e Ingeniería de Materiales e Ingeniería Química (IAAB), Universidad Carlos III de Madrid, 28911 Leganés, Madrid, Spain

${ }^{2}$ Department of Physics, Department of Chemistry, Department of Materials Science and Engineering, and Center for 2-Dimensional and Layered Materials, Eberly College of Science, The Pennsylvania State University, 104 Davey Lab., University Park, PA 16802, USA
}

\begin{abstract}
CVD synthesised CNT flexible sponge with density lower than $0.02 \mathrm{~g} \mathrm{~cm}^{-3}$ has been found to serve as high performance EMI shielding material without the aid of any polymer infil-tration or impregnation. Due to its extreme lightweight, the specific SE of the CNT-sponge was found to be as high as $1100 \mathrm{~dB} \mathrm{~cm}^{3} \mathrm{~g}^{-1}$, having a total SE above $20 \mathrm{~dB}$ in the whole $1-18 \mathrm{GHz}$ range, and being able to shield by absorption. The material is the best of our knowledge this specific SE value appears to be the highest reported hitherto. Improved EM ab-sorbers should fulfil the synergic requirements of being low reflective and highly absorptive.

In our CNT-sponges this condition is not satisfied because, although their net absorp-tion ability is strongly remarkable, their high electrical con-ductivity favours the wave to be reflected at the input inter-face. Therefore, this sponge material would have a great po-tential for microwave-frequency applications that need negli-gible reflection and great absorption when combined in a multilayered structure that could prevent the wave to be re-flected at the input interface.
\end{abstract}

Keywords electromagnetic shielding, carbon nanotubes, sponges, high dielectric losses

1 Introduction Parasite electromagnetic radiation has a negative impact in electronic devices because this radiation may interfere with the efficient operation of the devices. With the fast development of telecommunications, the technologies that operate in the microwave range need to find new suitable materials able to neutralize electromagnetic interference (EMI) in the $\mathrm{GHz}$ frequency range. Nowadays the protection of electronic devices towards external radiation could be accomplished either by reflecting the incident wave or by an absorption-dissipation process [1]. Reflection has been achieved for the past few decades with metal-based materials while the absorption process is still challenging because one needs to simultaneously accomplish low reflection and high absorption losses [2]. In addition to EMI shielding, lightweight, flexibility, processing easiness and low cost are necessary requirements that materials need in order to use them in flexible electronics, aerospace and automotive manufacturing [3]. In this context, polymer composites incorporating electrically conducting carbonaceous materials have gained increasing attention because they might be able to achieve most of these requirements [4], and in contrast to metallic EMI shields, they might be more prompt to absorb the incident radiation rather than reflecting it. This process could be even more efficient if the conducting fillers are combined with ferromagnetic nanoparticles [5]. Among several possibilities, carbonaceous particles might be able to serve as active microwave absorbers in polymer composites [6].

The shielding efficiency (SE) of composites fabricated with different carbonaceous nano-inclusions [4, 6] is enhanced with the electrical conductivity, and therefore depends on the nanofiller weight percentage as well as on 
their aspect ratio [7]. In this context, it has been shown that values of SE around $20 \mathrm{~dB}$ (desired value for most emerging applications) could be reached with $15 \mathrm{wt} \%$ of carbon black (CB), 5-10 wt\% carbon nanofibres (CNF) and only $2-3 \mathrm{wt} \%$ of multi-walled carbon nanotubes (MWCNTs) [8]. Furthermore, due to its high electrical conductivity and high specific surface area, chemically derived graphene has also been added to the list of carbon nanofillers in polymer matrixes for EMI shielding applications [9]. For example, the $\mathrm{SE}$ of a CVD-grown graphene monolayer has shown a value of $2.27 \mathrm{~dB}$, which corresponds to seven times the $\mathrm{SE}$ value of gold films exhibiting the same thickness [10].

Since the electrical conductivity of the composites depends on the dispersion degree of the nano-conductive filler [6], SE with values over $20 \mathrm{~dB}$ has been normally achieved with high filler loadings (e.g. $20 \mathrm{wt} \%$ ), a fact that is neither economically desirable nor viable for processing. In this context, there are only few published works in which this target SE value has been reported when using loads of 2-3 wt\% MWCNTs [8]. In most cases reasonable SE values have only been achieved with loadings up to $20 \mathrm{wt} \%$ [11] of single-walled CNT, 5wt\% and $10 \mathrm{wt} \%$ [12] of MWCNT or $15 \mathrm{wt} \%$ of chemically derived graphene [13].

It is worth emphasizing that high filler loadings are not suitable because the desired weight-reduction of the composites increases and high filler loads could induce unwanted particle agglomeration that significantly reduces the efficiency of the filler. It is therefore necessary to avoid high filler loadings and use alternative processes that assure excellent filler dispersions and interconnectivity. Some alternative approaches include 3-dimensional macroscopic assemblies exhibiting ultralow percolation thresholds [14], such as aerogels, carbon foams and scaffolds synthesized using CNTs and graphene materials [15]. These architectures can be subsequently infiltrated with polymers in order to increase their robustness while the conducting paths through the entire composite remain unaltered, thus maintaining high values of SE even for low filler loadings. Some examples of composite foams can be found in the literature using microcellular foams of graphene $(5 \mathrm{wt} \%)$ with electrical conductivities of $3.11 \mathrm{~S} / \mathrm{m}$ and SE values of $15 \mathrm{~dB}$ [16], ultra-light MWCNTs aerogels $(>1 \mathrm{wt} \%)$ with electrical conductivities of ca. 3.2 S/m [17], or CNTs and CNFs polystyrene composite foams in which SE values of $19 \mathrm{~dB}$ and $9 \mathrm{~dB}$ were achieved with loadings close to $7 \mathrm{wt} \%$ of CNTs and CNFs, respectively [18]. In some cases, these foams might have an additional advantage regarding EMI shielding by absorption-dissipation, as reported in MWCNT/polycaprolactone composites [19], in which the reflectivity was efficiently lowered using low CNT volume fractions when compared to solid composites having similar electrical conductivities. This reflection results from the mismatch of impedances at the propagating medium (air)/shield interface; the relative volume of air at the interface lowers the shield surface impedance, thus boosting the wave propagation within the material $[6,20]$.
Unfortunately, the connectivity of the fillers in most of these structures is limited, and so is the electrical conductivity, because the polymers used as the filler binder create resistive junctions. Hence, a reduction of the electrical resistivity at the insulating polymer interface between the conducting inclusions could enhance further the SE values. Indeed, a chemical vapour deposition (CVD) template route has been employed [21] to fabricate foams from graphene. This graphene-based 3-dimensional interconnected network has shown outstanding values of specific SE in the $\mathrm{X}$-band $\left(\sim 333 \mathrm{~dB} \mathrm{~cm}^{3} / \mathrm{g}\right)$ and electrical conductivities of about $100-120 \mathrm{~S} / \mathrm{cm}$. However, the procedure involves an additional polydimethylsiloxane (PDMS) impregnation step in order to synthesize the final material. Although the polymer does not interfere with the connectivity of the conducting nanomaterial, it does increase the density of the final electromagnetic absorber.

In this work we report the synthesis of a 3-dimensional isotropic CNT flexible sponge which could also be used as a unique high performance lightweight EMI shielding material. Our CNT-sponge exhibits a density $<0.02 \mathrm{~g} \mathrm{~cm}^{-3}$, with specific SE values $\sim 1100 \mathrm{~dB} \mathrm{~cm}^{3} \mathrm{~g}^{-1}$. Despite its light weight, the material is robust enough to be used without any polymer infiltration or impregnation, and to the best of our knowledge this SE value appears to be the highest reported hitherto.

Although, the synthesis and properties of CNT-sponges have been described in detail in some early published works [22, 23], they have never been studied as EMI shields. Only denser epoxy composites filled with analogously synthesized CNTs have been evaluated and found efficient as wide-band microwave absorbers [24].

\section{Methods}

\subsection{D/CNT-sponge synthesis}

2.1.1 Pristine or chlorine-doped sponge preparation $\mathrm{CNT}$-sponges were synthesized by chemical vapour deposition (CVD) in a horizontal furnace at $860^{\circ} \mathrm{C}$. Ferrocene and 1,2-dichlorobenzene (DCB) were used as catalyst and carbon source, respectively. The DCB solution with a catalyst concentration of $0.06 \mathrm{~g} / \mathrm{ml}$ was introduced into the furnace by injecting it at a constant rate of $0.18 \mathrm{ml} / \mathrm{min}$ into a preheated zone $\left(240^{\circ} \mathrm{C}\right)$ of the quartz tube. The vaporized mixture was then conducted into the $860{ }^{\circ} \mathrm{C}$ furnace zone (centre) by the carrier gas $\left(\mathrm{Ar} / \mathrm{H}_{2}\right.$, ratio $1: 0.15)$, which was set at a constant feeding rate of $2.6 \mathrm{~L} / \mathrm{min}$. The sponge material was then allowed to grow from $1 \mathrm{~h}$ to $2 \mathrm{~h}$ and the system was subsequently cooled to room temperature while maintaining the carrier gas flow at $0.5 \mathrm{~L} / \mathrm{min}$. Sponge thicknesses, when the growth was done for $2 \mathrm{~h}$, was typically $\sim 2-3.5 \mathrm{~mm}$.

3 Characterization Electrical properties of the composites were evaluated using a HP 34401A device with $100 \mu \Omega$ resolution and $10 \mathrm{G} \Omega$ upper limits. Measurements were performed in 4-wire DC configuration. The temperature of the samples during the measurement was $28.8^{\circ} \mathrm{C}$. 
The specimens were cut into squares $\left(\sim 8.5 \times 8.5 \mathrm{~mm}^{2}\right)$ or rectangular $\left(\sim 6.5 \times 3.5 \mathrm{~mm}^{2}\right)$ shapes with thickness of about $2.3-2.9 \mathrm{~mm}$. Top and bottom surfaces were carefully stuck to aluminium plates, serving as electrodes $\left(10 \times 10 \mathrm{~mm}^{2}\right)$, by applying a thin layer of silver paint over the plates and immediately contacting the sponge specimens. Raman spectroscopy measurements were done with a Renishaw Ramanscope, with a laser line of $514 \mathrm{~nm}$.

\subsection{Electromagnetic shielding efficiency tests A} vector network analyzer (Agilent, ENA, E5071) was used to measure the transmitted and reflected power $\left(P_{\mathrm{T}}\right.$ and $\left.P_{\mathrm{R}}\right)$ with an incident power $P_{\mathrm{I}}=1 \mathrm{~mW}$, in the range of $1 \mathrm{GHz}$ to $18 \mathrm{GHz}$ with a $7 \mathrm{~mm}$ coaxial transmission line adapter. The scattering parameters, $\mathrm{S}_{11}$ and $\mathrm{S}_{21}$ were used to calculate the complex permeability and permittivity of the CNTsponge which were obtained by the transmission/reflection method (agilent software). Samples were machined by plasma laser cutting to the requiered coaxial-line geometry: toroids shapes of internal and external diameters close to $3.04 \mathrm{~mm}$ and $7 \mathrm{~mm}$ respectively, and thickness in the range of $1.5-3 \mathrm{~mm}$. Using the built-in software, a geometry correction was applied for small deviations from nominal geometry.

4 Experimental The CVD synthesis of CNT sponges with thicknesses of ca. $2.8 \mathrm{~mm}$ is described in Section 2. The sponges were laser-machined into toroidal morpho- logies with internal and external diameters close to $3.04 \mathrm{~mm}$ and $7 \mathrm{~mm}$, respectively (see Fig. 1). Scanning electron microscopy (SEM) and transmission electron microscopy (TEM) images reveal that the material indeed consists of a highly interconnected and randomly distributed CNT network (see Fig. 1), and the tubes possess average diameters close of ca. $23 \mathrm{~nm}$ and lengths ranging from tens to hundreds of micrometers. Additionally, some inner residual particles can be found in some CNTs, corresponding mainly to iron carbide that remained after growth (see Fig. S1 in the Supporting Information, online at: www.pssrapid.com). The thermogravimetric analysis (TGA) showed that these particles constitute ca. $30 \mathrm{wt} \%$ of the total weight of the sponge material (see Fig. S2 of the Supporting Information). Moreover, the sponge material is ultralight (density $<0.02 \mathrm{~g} \mathrm{~cm}^{-3}$ ) and shows a nearly superhydrophobic behaviour (see Fig. S3 in the Supporting Information).

The DC-electrical conductivity (see Fig. 2) of the CNT-sponges was also measured in order to evaluate the electrical isotropy of the synthesized samples and the interconnectivity degree between adjacent CNTs. The measurements were carried out across the three dimensions of cubic samples (growth axes and transversal axes), and all of them exhibited a similar behaviour. The mean electrical conductivity was determined to be $278 \pm 18 \mathrm{~S} / \mathrm{m}$, which is in accordance with the reported values for this type of CNT-sponges, synthesized under similar conditions [22].
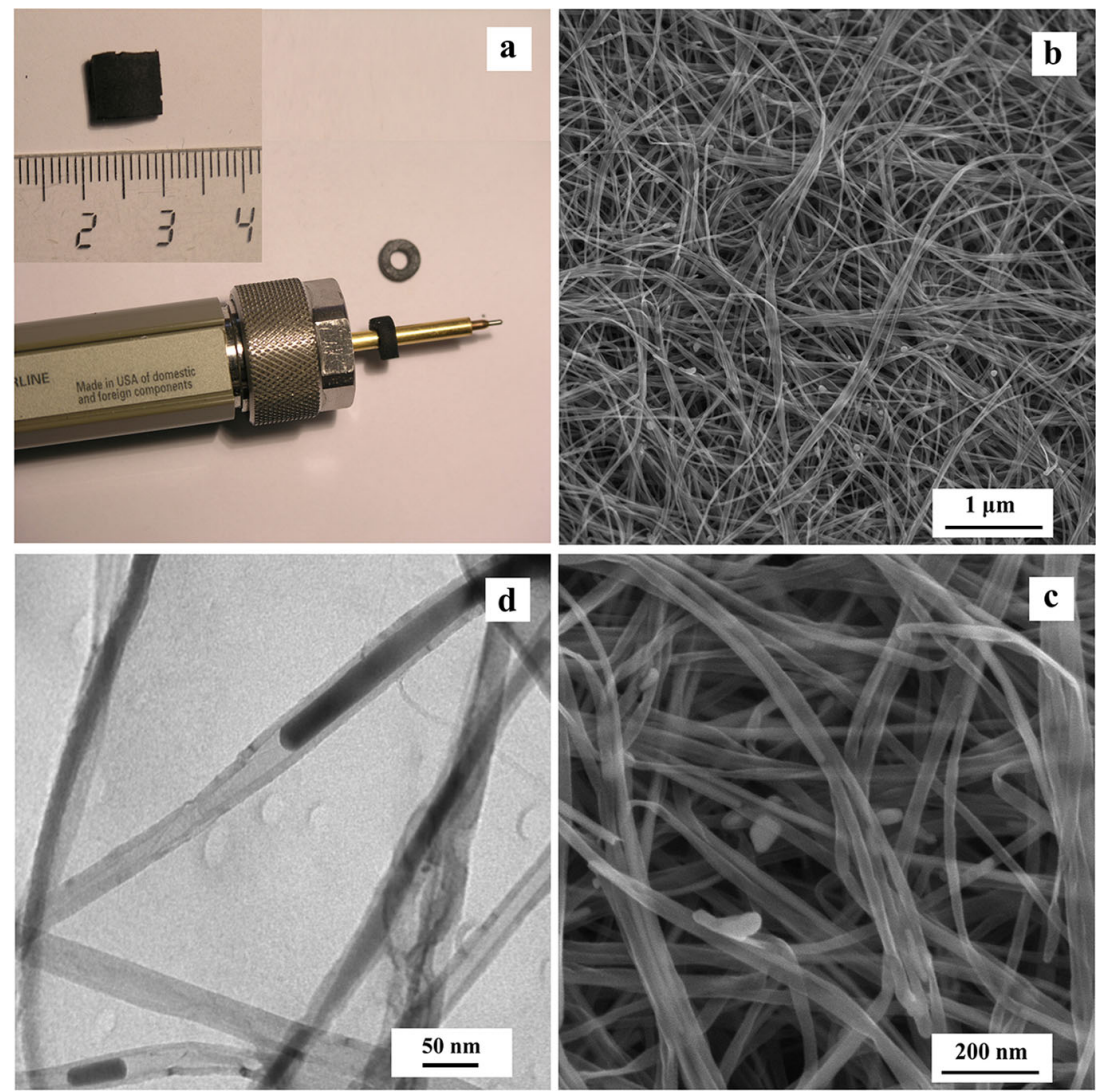

Figure 1 (a) Specimens and coaxial air line used for EMI shielding measurements. (b) and (c) SEM images of sponges. (d) TEM image of CNT that are forming the sponges. 


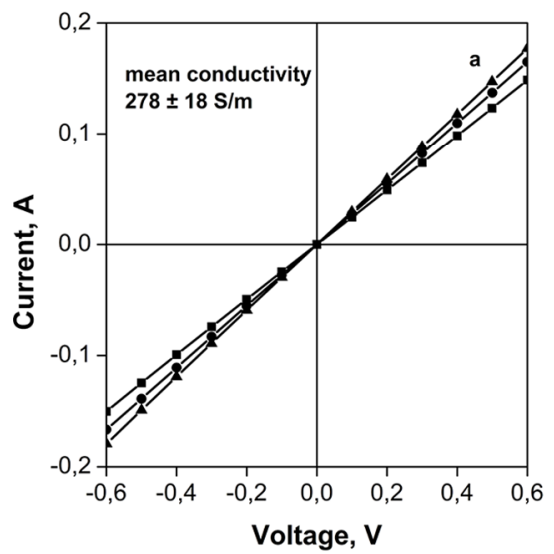

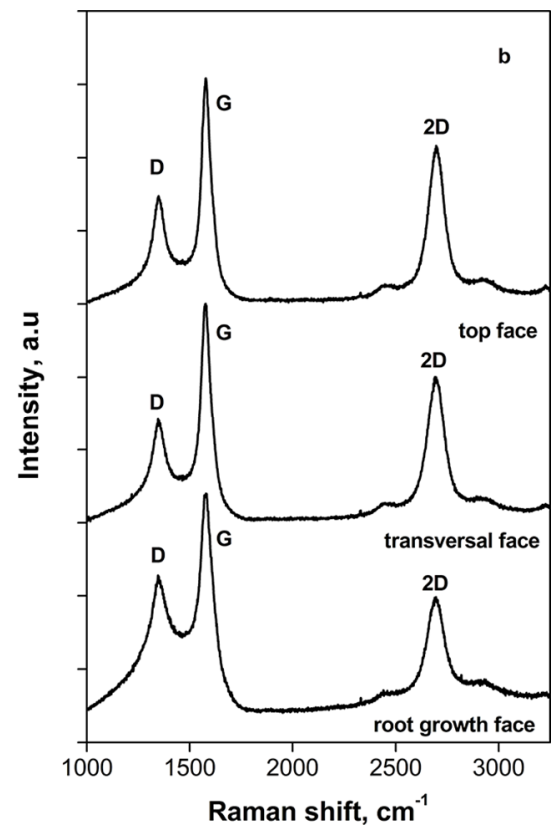

Figure 2 (a) $V-I$ plots for the three cross-sections of the CNT-sponge. From the slopes an average conductivity value of $278 \pm 18 \mathrm{Sm}^{-1}$ was obtained; (b) Raman spectra from the root growth face, transversal face and top face.
Raman spectroscopy studies were also performed to evaluate the chemical isotropy of the samples. As shown in Fig. 2, spectra of all three cross-sections reveal the typical D- and G-bands located at $1345-1350 \mathrm{~cm}^{-1}$ and $1579 \mathrm{~cm}^{-1}$, respectively, which are associated to degree of disorder within $\mathrm{sp}^{2}$ hybridized carbon structures (D-band), and the tangential mode of the $\mathrm{sp}^{2}$ carbon hexagonal lattice (G-band). Slight variations in the intensity ratio between D and $\mathrm{G}$ bands $\left(I_{\mathrm{D}} / I_{\mathrm{G}}\right)$ were observed for the root growth $\left(I_{\mathrm{D}} / I_{\mathrm{G}}=0.67\right)$ and top faces $\left(I_{\mathrm{D}} / I_{\mathrm{G}}=0.51\right)$ of the samples. These differences were attributed to a higher proportion of defects in the root growth face, which is exposed for longer times than the top face to the chlorine radicals formed by decomposition of the dichlorobenzene precursor.

The total electromagnetic shielding $\left(\mathrm{SE}_{\mathrm{T}}\right)$ and the contributions to reflection $\left(\mathrm{SE}_{\mathrm{R}}\right)$ and absorption $\left(\mathrm{SE}_{\mathrm{A}}\right)$ are given by Eqs. (S1)-(S3) in the Supporting Information [25]. These equations are valid when the thickness of the slab is greater than the skin depth $(\delta)$. At a low frequency $(1 \mathrm{GHz})$, the calculated skin depth is lower than the CNT-sponge thickness. Hence, the reflection at the inner output interface can be assumed to be absorbed by the conducting material and, consequently, multiple reflections can be neglected [14].

Evaluation of $\mathrm{SE}_{\mathrm{T}}$ for our CNT-sponges yields values that depend on the sponge thickness. $\mathrm{SE}_{\mathrm{T}}$ values for the $2.38 \mathrm{~mm}$ thick CNT-sponge slab (Fig. 3) correspond to $22 \mathrm{~dB}$ in almost the entire frequency window $(1-18 \mathrm{GHz})$, being absorption the dominant attenuation mechanism and no difference was observed with the sponge orientation. Since our synthesized CNT-sponges possess extremely low densities lower than $0.02 \mathrm{~g} \mathrm{~cm}^{-3}$, comparisons with other lightweight EMI shields should be addressed using specific shielding efficiency (SEE), which is given in $\mathrm{dB} \mathrm{cm}^{3} \mathrm{~g}^{-1}$. The SSE for our CNT-sponges reach values ranging between 550 (for the $1.56 \mathrm{~mm}$ thick slab) and $1100 \mathrm{~dB} \mathrm{~cm}^{3} \mathrm{~g}^{-1}$ (for the $2.38 \mathrm{~mm}$ thick slab), which are higher than those reported for a number of systems as shown in Table 1.

EMI shielding was evaluated further by analyzing the relative complex permittivity (see Fig. 3). The real and imaginary components represent the storage and loss of the EM energy, respectively, and can be assessed as dielectric interactions between the EM field and the shielding material. The confirmation that the CNT-network exhibits a high connectivity degree is that in the low-frequency range, the imaginary permittivity, which is a direct measure of the dielectric loss of the sample (also representing the polarizability), is higher than the real component. It is noteworthy that enhanced polarization processes have been widely observed in highly $(\sim 15-20 \mathrm{wt} \%)$ loaded CNTpolymer composites because in such systems there is a huge number of interfaces and grain boundaries that contribute to space charge polarization and thus, the real permittivity is higher than the imaginary one [30]. For these systems, in the low frequency regime, polarization prevails

Table 1 Specific shielding efficiency of carbon composites reported.

\begin{tabular}{lcc}
\hline system & $\mathrm{SSE}\left(\mathrm{dB} \mathrm{cm}^{3} \mathrm{~g}^{-1}\right)$ & Ref. \\
\hline CNT/polycaprolactone & 324 & {$[19]$} \\
CNT/polystyrene & 33.1 & {$[18]$} \\
graphene/ PDMS & 330 & {$[21]$} \\
carbon foam decorated with MWCNTs & 64.4 & {$[26]$} \\
graphene/polyetherimide & 44.1 & {$[27]$} \\
graphene/polystyrene & 64.4 & {$[28]$} \\
commercial carbon foams & $147-176$ & {$[29]$} \\
CNT-sponge (present work) & 1100 & \\
\hline
\end{tabular}



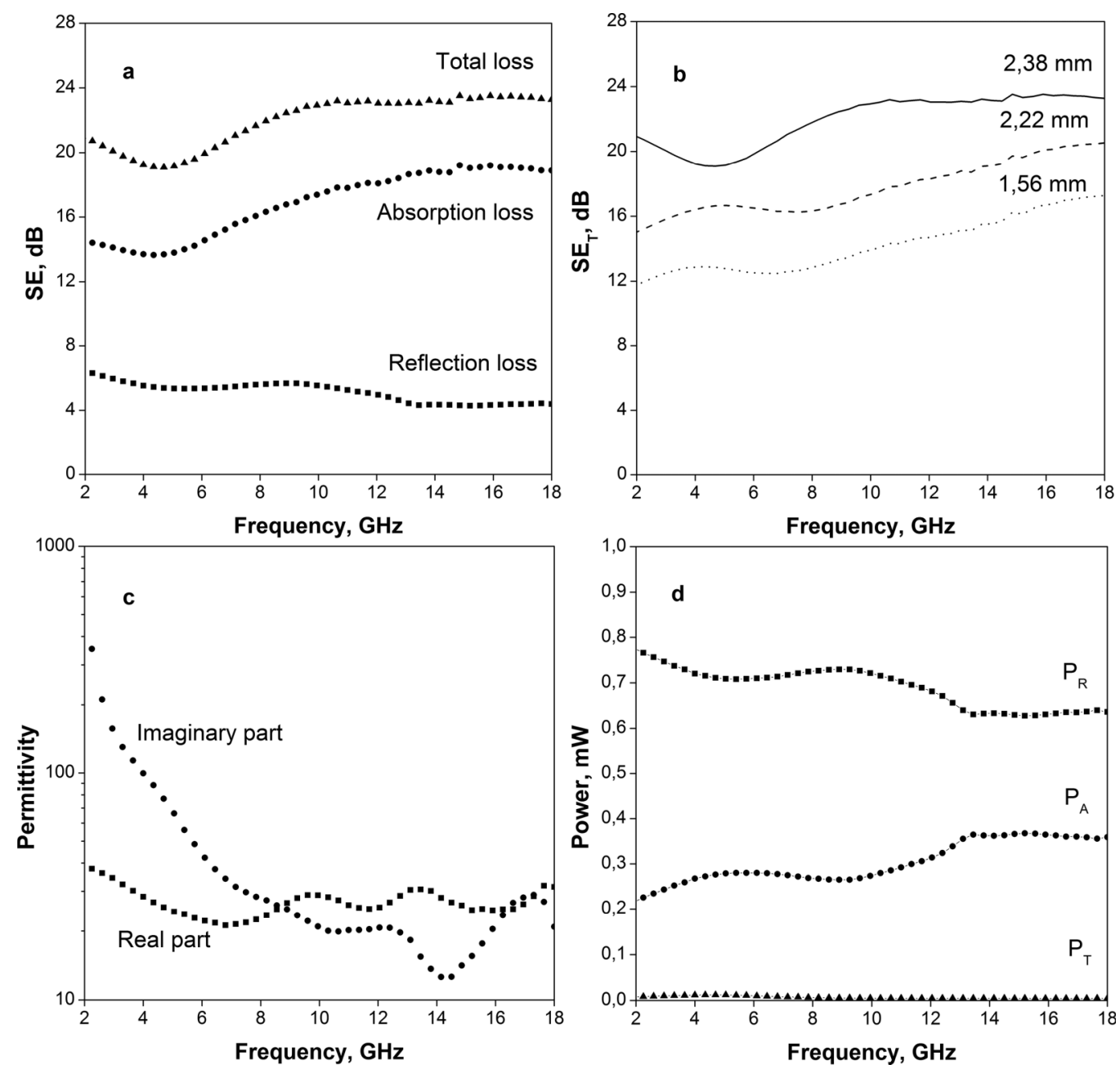

Figure 3 Electromagnetic properties in $\mathrm{GHz}$ range: (a) electromagnetic shielding efficiency component in sponge thickness $(2.38 \mathrm{~mm})$; (b) electromagnetic transmission losses in sponges with different thickness; (c) complex permittivity, and (d) power balance in sponge thickness $(2.38 \mathrm{~mm})$

over the resistive loss, whereas for the CNT-sponges the opposite occurs: the resistive loss is dominant because the conductive paths lack from capacitive barriers. Moreover, the real permittivity presents low values along all the swept frequencies, which is noteworthy for a material composed of highly conducting CNT percolating networks. According to the effective medium theory, the permittivity of the material will have the contribution of both, air and CNTs, and hence, its value will be lower than that of a material exhibiting analogous conductivity values but being compact or non-porous [20]. The material lightness might enable its correlation with the dielectric properties found in aerogels and foams. Theories of Hrubesh and Pekala state that in general, these structures might exhibit low dielectric properties, which can be more accurately described rather by a gas-like behaviour than by a solid-like one and will strongly depend on the relative density of the bulk [31]. It has been corroborated that the effective permittivity of aerogels, with almost all phase combinations, geometries and distributions, are circumscribed between the Wiener bounds, which are the less restrictive and depend on the volume fraction and the complex permittivity of each phase in the composite. It is hence clear that for materials containing high volume fractions of air, the effective permittivity of the composite should lay somewhere close to the lowest permittivity bound but obviously restricted by the intrinsic permittivity of the filler [32]. From the above presented relationships, it might be plausible to think that due to the extremely low density of the CNT-sponge, the dielectric properties (permittivity) might be governed, at least partially, by the dielectric matrix (air) filling the gaps within the nanotube network.

As established in previous works [5], it is worth to contrast the overall $\mathrm{SE}$ and its contributions $\left(\mathrm{SE}_{\mathrm{A}}\right.$ and $\left.\mathrm{SE}_{\mathrm{R}}\right)$ with the balance of the absolute values of incident, transmitted, absorbed and reflected powers $\left(P_{\mathrm{A}}=P_{\mathrm{I}}-P_{\mathrm{T}}-P_{\mathrm{R}}\right.$; $\left.P_{\mathrm{I}}=1 \mathrm{~mW}\right)$. The results for the $2.38 \mathrm{~mm}$ thick CNTsponge slab are shown in Fig. 3. It can be seen that for all measured frequencies, power blocked by reflection is higher than that by absorption, which is a logic conse- 
quence of reflection happening before absorption, thus leaving a lower amount of non-reflected power to be transmitted into the sample. This observation is consistent with the high electrical conductivity value recorded for the sample, which is expected to increase the reflectivity at the outer input interface, but does not imply that reflection dominates the EMI shielding mechanism within the CNTsponges, as indicated in the shielding efficiency analysis.

5 Conclusion In this work a CNT flexible sponge with density lower than $0.02 \mathrm{~g} \mathrm{~cm}^{-3}$ has been found to serve as high performance EMI shielding material without the aid of any polymer infiltration or impregnation. Due to its extreme lightweight, the specific SE of the CNT-sponge was found to be as high as $1100 \mathrm{~dB} \mathrm{~cm}^{3} \mathrm{~g}^{-1}$, having a total SE above $20 \mathrm{~dB}$ in the whole $1-18 \mathrm{GHz}$ range, and being able to shield by absorption. Improved EM absorbers should fulfil the synergic requirements of being low reflective and highly absorptive. In our CNT-sponges this condition is not satisfied because, although their net absorption ability is strongly remarkable, their high electrical conductivity favours the wave to be reflected at the input interface. Therefore, this sponge material would have a great potential for microwave-frequency applications that need negligible reflection and great absorption when combined in a multilayered structure that could prevent the wave to be reflected at the input interface.

Acknowledgements This work was supported by Nanomod (MAT2010-17091) from the Spanish Ministerio de Ciencia e Innovación. MT acknowledges the financial support from the MURI project awards Nos. FA9550-12-1-0035 and FA9550-121-0471. MT also thanks JST-Japan for funding the Research Center for Exotic Nano Carbons, under the Japanese Regional Innovation Strategy Program by the Excellence.

\section{References}

[1] D. D. L. Chung, Carbon 39, 279 (2001).

[2] A. N. Yusoff, M. H. Abdullah, S. H. Ahmad, S. F. Jusoh, A. A. Mansor, and S. A. A. Hamid, J. Appl. Phys. 92, 876 (2002).

[3] X. C. Tong, Advanced Materials and Design for Electromagnetic Interference Shielding (Francis \& Taylor, Boca Raton, 2009).

[4] J. M. Thomassin, C. Jérôme, T. Pardoen, C. Bailly, I. Huynen, and C. Detrembleur, Mater. Sci. Eng. R 74, 211 (2013).

M. F. L. De Volder, S. H. Tawfick, R. H. Baughman, and A. John Hart, Science 339, 535 (2013).

[5] M. Crespo, M. González, J. Baselga, and J. Pozuelo, Carbon 74, 63 (2014).

R. Che, L. M. Peng, X. Duan, Q. Chen, and X. Liang, Adv. Mater. 16, 401 (2004).

P. F. Guan, X. F. Zhang, and J. J. Guo, Appl. Phys. Lett. 101, 153108 (2012).

H. M. Kim, K. Kim, C. Y. Lee, J. Joo, S. J. Cho, H. S. Yoon, D. A. Pejaković, J. W. Yoo, and A. J. Epstein, Appl. Phys. Lett. 84, 589 (2004).
[6] F. Qin and C. Brosseau, J. Appl. Phys. 111, 061301 (2012). C. Brosseau, W. N. Dong, and A. Mdarhri, J. Appl. Phys. 104, 074907 (2008).

B. J. P. Adohi, A. Mdarhri, C. Prunier, B. Haidar, and C. Brosseau, J. Appl. Phys. 108, 074108 (2010).

[7] Y. Huang, N. Li, Y. Ma, F. Du, F. Li, X. He, X. Lin, H. Gao, and Y. Chen, Carbon 45, 1614 (2007).

[8] M. H. Al-Saleh, W. H. Sadaah, and U. Sundararaj, Carbon 60, 146 (2013).

[9] X. Bai, Y. Zhai, and Y. Zhang, J. Phys. Chem. C 115, 11673 (2011).

W. L. Song, M. S. Cao, M. M. Lu, S. Bi, C. Y. Wang, J. Liu, J. Yuan, and L. Z. Fan, Carbon, DOI: http://dx.doi.org/10.1016/j.carbon.2013.08.043 (2013).

J. Liang, Y. Wang, Y. Huang, Y. Ma, Z. Liu, J. Cai, C. Zhang, H. Gao, and Y. Chen, Carbon 47, 922 (2009). C. Wang, X. Han, P. Xu, X. Zhang, Y. Du, S. Hu, J. Wang, and X. Wang, Appl. Phys. Lett. 98, 072906 (2011).

[10] S. K. Hong, K. Y. Kim, T. Y. Kim, J. H. Kim, S. W. Park, J. H. Kim, and B. J. Cho, Nanotechnology, 23, 455704 (2012).

[11] N. Li, Y. Huang, F. Du, X. He, X. Lin, H. Gao, Y. Ma, F. Li, Y. Chen, and P. C. Eklund, Nano Lett. 6, 1141 (2006). Y. Huang, N. Li, Y. Ma, F. Du, F. Li, X. He, X. Lin, H. Gao, and Y. Chen, Carbon 45, 1614 (2007).

Z. Liu, G. Bai, Y. Huang, Y. Ma, F. Du, F. Li, T. Guo, and Y. Chen, Carbon 45, 821 (2007).

N. C. Das, Y. Liu, K. Yang, W. Peng, S. Maiti, and H. Wang, Polym. Eng. Sci. 49, 1627 (2009).

[12] M. Arjmand, T. Apperley, M. Okoniewski, and U. Sundararaj, Carbon 50, 5126 (2012).

R. B. Mathur, S. Pande, B. P. Singh, and T. L. Dhami, Polym. Compos. 29, 717 (2008).

[13] J. Liang, Y. Wang, Y. Huang, Y. Ma, Z. Liu, J. Cai, C. Zhang, H. Gao, and Y. Chen, Carbon 47, 922 (2009).

[14] F. Irin, S. Das, F. O. Atore, and M. J. Green, Langmuir 29, 11449 (2013).

[15] S. Nardecchia and D. Carriazo, Chem. Soc. Rev. 42, 794 (2013).

C. Li and G. Shi, Nanoscale 4, 5549 (2012).

[16] H. B. Zhang, Q. Yan, W. G. Zheng, Z. He, and Z. Z. Yu, ACS Appl. Mater. Interf. 3, 918 (2011).

[17] J. Zou, J. Liu, A. S. Karakoti, A. Kumar, D. Joung, Q. Li, S. I. Khondaker, S. Seal, and L. Zhai, ACS Nano 4, 7293 (2010).

[18] Y. Yang and M. C. Gupta, Nano Lett. 5, 2131 (2005).

[19] J. M. Thomassin and C. Pagnoulle, J. Mater. Chem. 18, 792 (2008).

[20] Q. Liu, D. Zhang, and T. Fan, Appl. Phys. Lett. 93, 013110 (2008).

[21] Z. Chen and C. Xu, Adv. Mater. 25, 1296 (2013).

[22] X. Gui, J. Wei, K. Wang, A. Cao, H. Zhu, Y. Jia, Q. Shu, and D. Wu, Adv. Mater. 22, 617 (2010).

[23] D. P. Hashim, N. T. Narayanan, J. M. Romo-Herrera, D. A. Cullen, M. G. Hahm, P. Lezzi, J. R. Suttle, D. Kelkhoff, E. Munoz-Sandoval, S. Ganguli, A. K. Roy, D. J. Smith, R. Vajtai, B. G. Sumpter, V. Meunier, H. Terrones, M. Terrones, and P. M. Ajayan, Sci. Rep. 2, 363 (2012).

X. Gui, H. Li, L. Zhang, Y. Jia, L. Liu, Z. Li, J. Wei, K. Wang, H. Zhu, Z. Tang, D. Wu, and A. Cao, ACS Nano 5, $4276(2011)$. 
H. Li, X. Gui, L. Zhang, S. Wang, C. Ji, J. Wei, K. Wang, H. Zhu, D. Wu, and A. Cao, Chem. Commun. 46, 7966 (2010).

X. Gui, A. Cao, J. Wei, H. Li, Y. Jia, Z. Li, L. Fan, K. Wang, H. Zhu, and D. Wu, ACS Nano 4, 2320 (2010).

X. Gui, H. Li, K. Wang, J. Wei, Y. Jia, Z. Li, L. Fan, A. Cao, H. Zhu, and D. Wu, Acta Mater. 59, 4798 (2011).

Z. Zeng, X. Gui, Z. Lin, L. Zhang, Y. Jia, A. Cao, Y. Zhu,

R. Xiang, T. Wu, and Z. Tang, Adv. Mater. 25, 1185 (2013).

X. Gui, Z. Lin, Z. Zeng, K. Wang, D. Wu, and Z. Tang, Nanotechnology 24, 085705 (2013).

H. Li, X. Gui, C. Ji, P. Li, Z. Li, L. Zhang, E. Shi, K. Zhu, J. Wei, K. Wang, H. Zhu, D. Wu, and A. Cao, Nano Res. 5, 265 (2012).

X. Tang, X. Gui, Y. Liu, and B. Wang, RSC Adv. 3, 14473 (2013).

[24] R. Lv, F. Kang, J. Gu, X. Gui, J. Wei, K. Wang, and D. Wu, Appl. Phys. Lett. 93, 223105 (2008).
[25] M. H. Al-Saleh and U. Sundararaj, Carbon 47, 1738 (2009).

[26] R. Kumar, S. R. Dhakate, T. Gupta, P. Saini, B. P. Singh, and R. B. Mathur, J. Mater. Chem. A 1, 5727 (2013).

[27] J. Ling, W. Zhai, W. Feng, B. Shen, J. Zhang, and W. Zheng, ACS Appl. Mater. Interf. 5, 2677 (2013).

[28] D. X. Yan, P. G. Ren, H. Pang, Q. Fu, M. B. Yang, and Z. M. Li, J. Mater. Chem. 22, 18772 (2012).

[29] F. Moglie, D. Micheli, S. Laurenzi, M. Marchetti, and V. M. Primiani, Carbon 50, 1972 (2012).

[30] C. A. Grimes, C. Mungle, D. Kouzoudis, S. Fang, P. C. Eklund, Chem. Phys. Lett. 319, 460 (2000).

[31] L. W. Hrubesh, L. E. Keene, and V. R. Latorre, J. Mater. Res. 8, 1736 (1993).

[32] X. Xiao, R. Streiter, G. Ruan, R. Song, T. Otto, and T. Gessner, Microelectron. Eng. 54, 295 (2000).

F. Moglie, D. Micheli, S. Laurenzi, M. Marchetti, and V. Mariani Primiani, Carbon 50, 1972 (2012). 